\title{
Dirty Secret-A Case Study
}

\author{
Bapi Saha, Ajitesh Pal* and HK Pratihari \\ Tripura State Forensic Science Laboratory, India
}

Submission: February 01, 2018; Published: March 15, 2018

*Corresponding author: Ajitesh Pal, Tripura State Forensic Science Laboratory, India, Email: ajiteshp@rediffmail.com

\begin{abstract}
The sexual related crime scenario in the country is very alarming. As per report of the NCRB (National Crime Record Bureau), MHA, Govt. of India every 20 minutes, one rape case is reported in India. In-spite of stringent punishment under various sections of IPC (Indian Penal Code) and other laws, the sex crime with electronic tools like smart phone, i-pod, tablet and laptop etc. are also frequently reported. These tools are easily misused to record/store obscene picture to motivate the young girls for sex activities. Many such cases are reported against friend, teacher, relative, neighbour and co-worker in the society. In one case, a 9-year old girl was admitted in an English medium school. The principal taking advantage of the age of the girl, often used to call her to his residential room inside the school campus and showing her child porn from electronic mobile (Tablet). Further, the principal had also sex several times with the girl and recorded the obscene act in his tablet in video form. The underage girl being disturbed, insisted her parents not to study further in the same school. Knowing such reluctance, the parents tried to know the reason and ultimately, the girl narrated the sexual assault on her, committed by the principal. Thereafter, parents lodged a complaint to the police. In the course of investigation, forensic team visited the spot and medical examination of the victim girl was also done. The forensic evidence collected were examined to establish the fact and detailed discussion has been made in this paper.
\end{abstract}

Keywords: Tablet; Obscene picture; Sexual assault; Medical examination; Crime spot; Pattern recognition

Abbreviations: NCRB: National Crime Record Bureau; IPC: Indian Penal Code

\section{Introduction}

All over the world in all life situation women, minor girls are more vulnerable than men in public and private life. As per National Crime Records Bureau (NCRB) report of the year 2011, it is known that every 20 minutes, a woman is raped in India [1]. This is really alarming figure and various crime against women reported are shown in the capsule form (Figure 1). The conviction in the crime against women in India is reported to be $18.9 \%$ in the year 2015 as per report of 'The Indian Express' [2]. The conviction rate is not at desire level for following reasons:

a) No exemplary punishment for such crime

b) Lack of civic activities

c) Lack of quality investigation and powerful tools

d) In effective criminal justice system due to poor performance

e) Lack of corroborative evidence

f) In-sufficient preventive measures

g) Media

The incident of such crime is sometime available in digital form and useful for establishing the fact and also to identify the place of incidence and accused/victim [3,4]. The digital recording device like Tablet, I-pod, Mobile, Laptop, CCTV etc. are very often received for forensic examination to establish the crime and criminal in many cases.

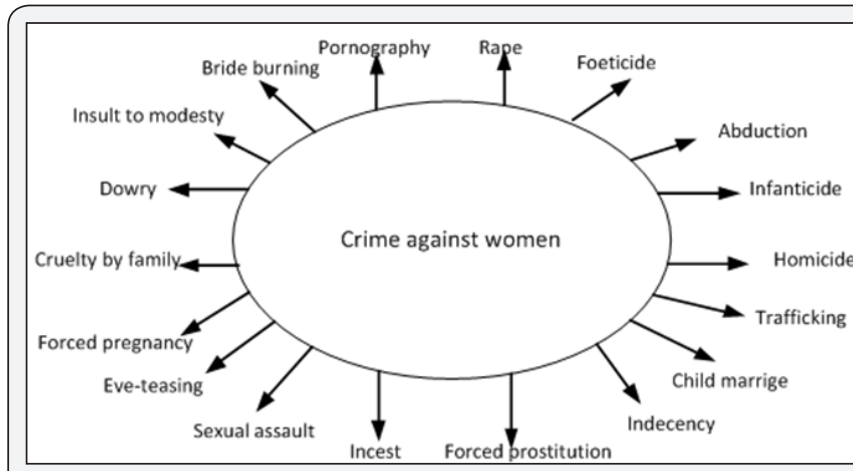

Figure 1.

\section{Case Report}

A girl age about 9-year was admitted in a residential English medium school and staying inside school campus with other friends. Occasionally, the principal used to call the victim girl to his residential room to show child pornography. Subsequently, she was also sexually assaulted. Since she was helpless having 
fear and shame, could not share such incident with anybody and passing the days with disturbed mind. One day, the victim girl insisted her parents not to continue her study in that school and motivated them to admit in any other schools. On hearing such objection, the parents wanted to change her mind, but the girlchild was rigid in her decision. Further, the parents were anxious to know the actual fact and without hesitation, she narrated the sexual assault on her being committed by the principal. Thereafter, the parents lodged complaints to the police. In the course of investigation, police could seize the tablet from the accused for forensic examination and the girl was also examined by the medico legal surgeon to establish the fact.

\section{Materials and Methods}

In this case one tablet and the vaginal swab of the victim girl and photograph of both victim and accused were received for examination. On examination of the tablet some objectionable video files were detected and retrieved with the help of digital forensic analysis software. From the video files some of the frames (images) were generated and shown in the (Figures 2-6). Many of the frames are not shown in the paper to avoid the effect on moral of the victim. However, some of the images available in the tablet confirmed the crime spot [3-4] on the basis of comparison of photograph collected during spot visit by the forensic team.

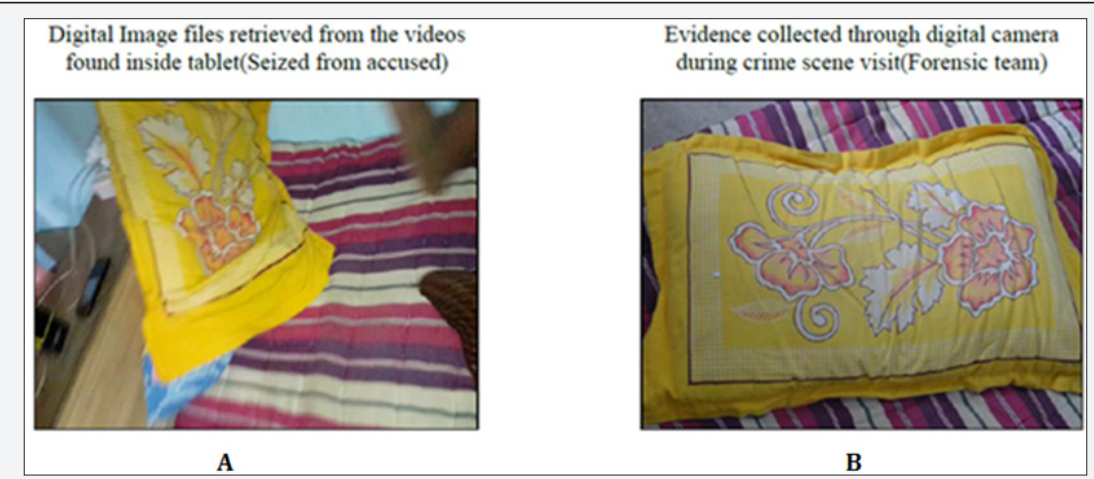

Figure 2. A: Photograph of pillow and handmade mattress B: Photogragh of identical pillow and mattress.

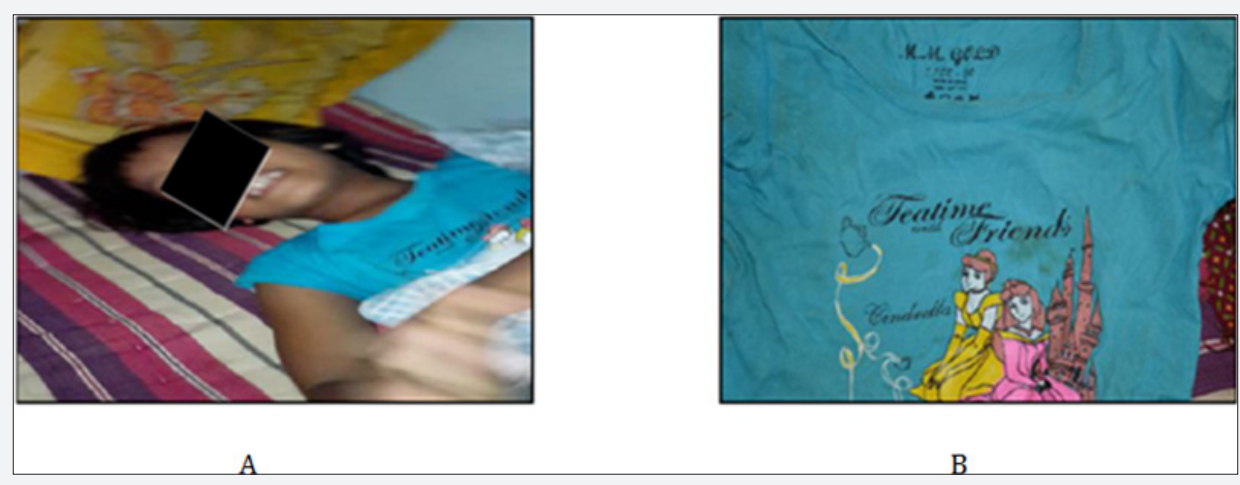

Figure 3. A: Photograph of the victim girl lying on the bed wearing tiffany blue colour top written "Tea time with friends" B: Photograph of identical top seized during crime scene visit.

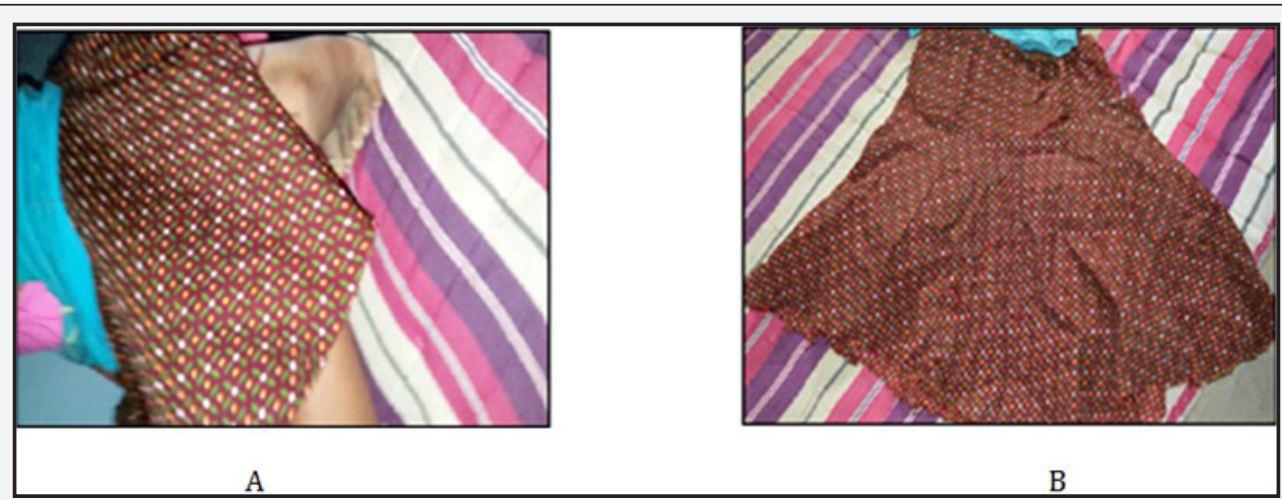

Figure 4. A: Photograph of the victim girl lying on the bed wearing printed dotted skirt B: Photograph of identical dotted skirt found at scene of crime. 


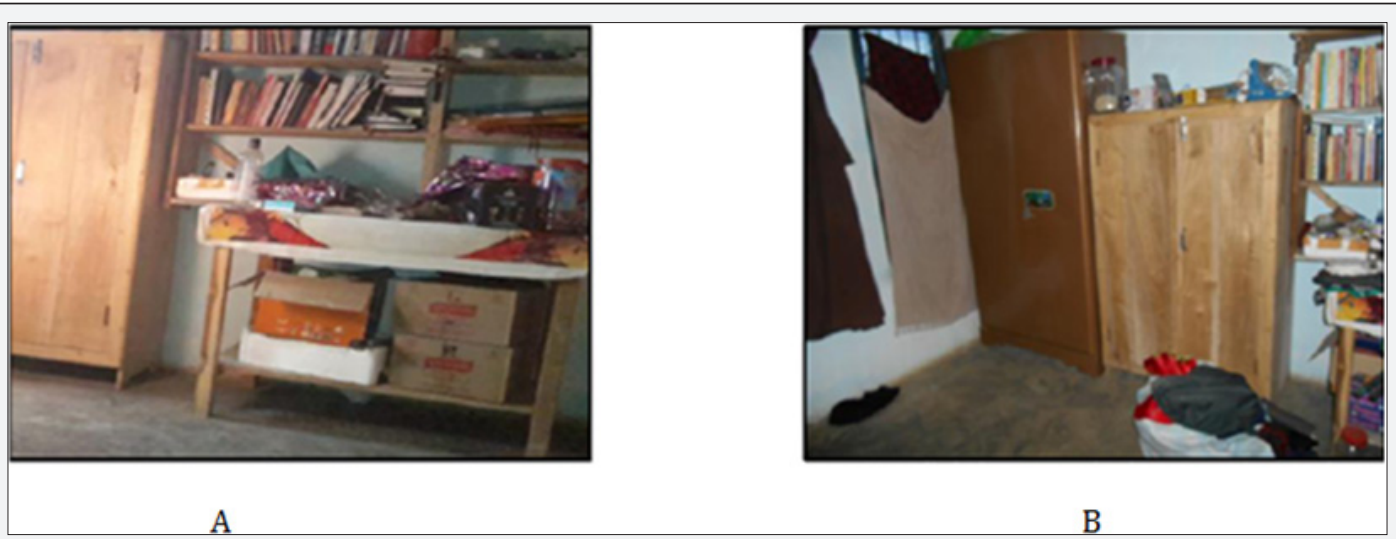

Figure 5. A: Photograph of almirah and book shelve showing inside the room (victim being abused) B: Photograph showing identical almirah and book shelve inside the room(place of incident) taken during crime scene visit.

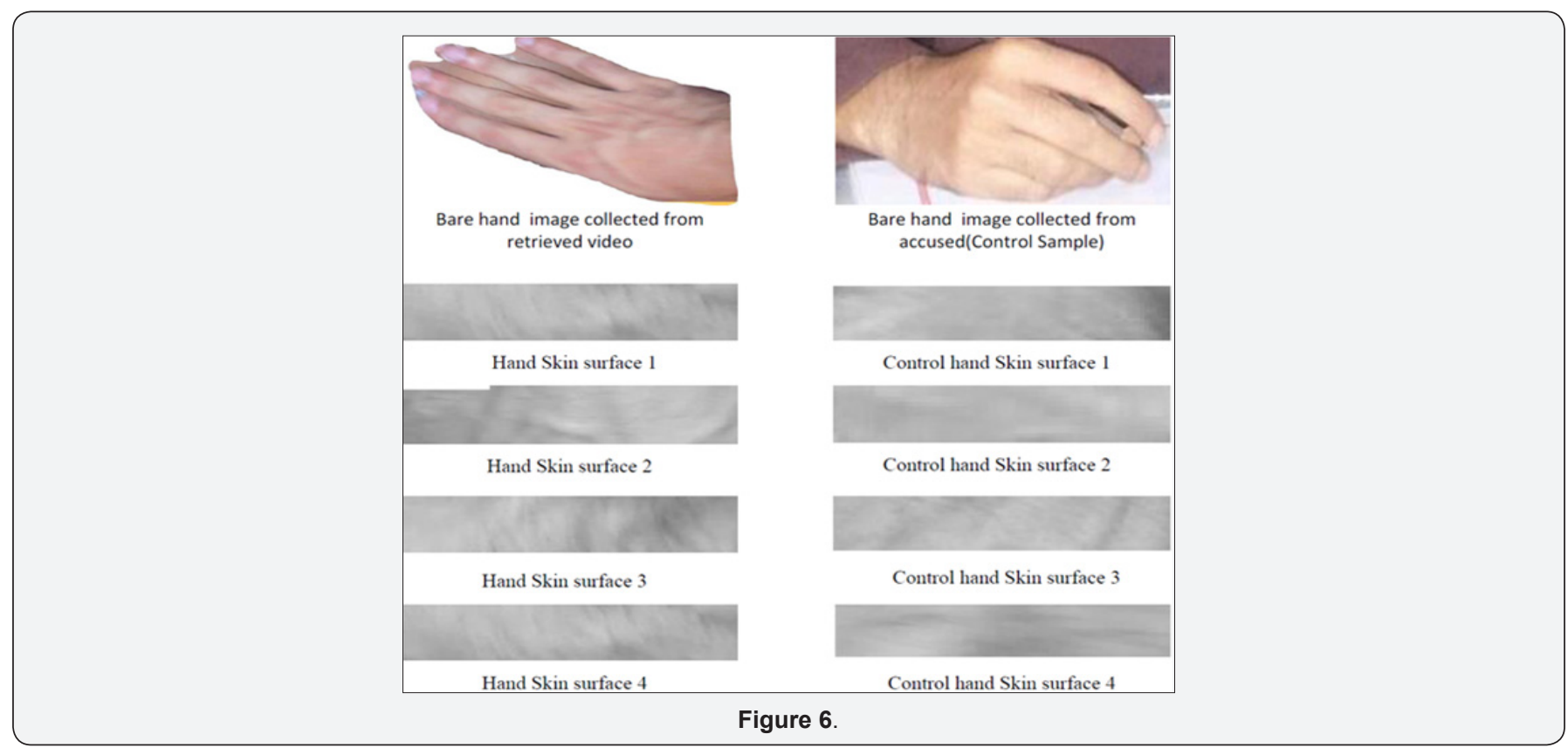

The videos retrieved from the tablet was devoid of face of the accused in the file but some portion of the body like hand and leg were shown recorded with the victim girl. Some control samples (digital image) of the accused hand were also received for examination. Considering the availability of the hand images some digital image processing features of the skin were taken for skin texture analysis [4-6] like smoothness, mean area, standard deviation, entropy, DC components of the skin surface using Matlab version 8.01 software [7-8]. The results of the analysis have been shown below in Table-1.

The observations in the Table-1 showing different parameters value conclusively prove the hand images available in the videos to be identical with the control hand image samples taken from accused. The little deviation in the average value on different parameters is due to different light condition/environmental condition prevailed at the time photograph collection.

\section{Conclusion}

In this case, the incident took place in the living room of the accused inside the school campus and the accused further recorded the sex act in his own tablet to enjoy the sadistic pleasure later. But on the basis of FIR, the forensic team and police officer visited the spot(living room of accused) and collected photograph at different angles and seized other physical evidence like tablet, desktop, mobile etc. The examination of tablet could reveal some incident related videos which were compared with digital photographs collected by the forensic team. On comparison the crime spot was identified to be living room of the accused where the incident took place. The analysis of digital photographs was not sufficient to corroborate the incident, hence the skin surface texture analysis method was adopted available in video frame/ control image to strengthen the evidence. The analysis made on the observation shown in the Table 1 proved beyond doubt about the involvement of the accused in this case. 
Table 1.Feature Extraction and Analysis

\begin{tabular}{|c|c|c|c|c|c|}
\hline $\begin{array}{l}\text { Image } \\
\text { (Surface of skin } \\
\text { from bare hand } \\
\text { collected from the } \\
\text { retrieved video) }\end{array}$ & Mean value & Standard deviation & Smoothness Index & Entropy & DC Component \\
\hline Hand Skin surface 1 & 0.7057 & 0.0094 & 0.0001 & 5.3678 & 0.7057 \\
\hline Hand Skin surface 2 & 0.6979 & 0.0081 & 0.0001 & 5.8163 & 0.6979 \\
\hline Hand Skin surface 3 & 0.6955 & 0.0112 & 0.0001 & 5.9211 & 0.6955 \\
\hline Hand Skin surface 4 & 0.7035 & 0.011 & 0.0001 & 5.3181 & 0.7035 \\
\hline $\begin{array}{c}\text { Image } \\
\text { (Surface of skin } \\
\text { from bare hand } \\
\text { collected from } \\
\text { accused as control } \\
\text { sample) }\end{array}$ & Mean value & Standard deviation & Smoothness Index & Entropy & DC Component \\
\hline $\begin{array}{l}\text { Control hand skin } \\
\text { surface } 1\end{array}$ & 0.7 & 0.0097 & 0.0001 & 5.8695 & 0.7 \\
\hline $\begin{array}{c}\text { Control hand skin } \\
\text { surface } 2\end{array}$ & 0.7149 & 0.0104 & 0.0001 & 5.2876 & 0.7149 \\
\hline $\begin{array}{c}\text { Control hand skin } \\
\text { surface } 3\end{array}$ & 0.7011 & 0.0098 & 0.0001 & 5.4377 & 0.7011 \\
\hline $\begin{array}{l}\text { Control hand skin } \\
\text { surface } 4\end{array}$ & 0.687 & 0.0088 & 0.0001 & 5.7624 & 0.687 \\
\hline Average value & Average Mean value & $\begin{array}{c}\text { Average Standard } \\
\text { deviation }\end{array}$ & $\begin{array}{l}\text { Average Smoothness } \\
\text { Index }\end{array}$ & Average Entropy & $\begin{array}{l}\text { Average DC } \\
\text { Component }\end{array}$ \\
\hline $\begin{array}{l}\text { Retrieved hand skin } \\
\text { surface }\end{array}$ & 0.70065 & 0.009925 & 0.0001 & 5.605825 & 0.70065 \\
\hline Control hand surface & 0.70075 & 0.009675 & 0.0001 & 5.5893 & 0.70075 \\
\hline
\end{tabular}

\section{References}

1. https://in.reuters.com/article/india-delhi-gang-rape-women-safetypolic/analysis-how-indias-police-and-judiciary-fail-rape-victimsidINDEE90F0AY20130116.

2. http://indianexpress.com/article/india/crimes-against-women-21per-cent-of-accused-convicted-in-2015-4433282.

3. Edward M Robinson (2016) Crime Scene Photography. ( $3^{\text {rd }}$ edn), Academic Press, USA.

4. Min L, Gao L, X Zhang, Wang Z (2014) Surface roughness measurement based on image texture analysis. $20147^{\text {th }}$ International Congress on Image and Signal Processing, Dalian, pp. 514-519.
5. Srivani A, Anthony Xavior M (2014) Investigation of surface structure using Image processing techniques. $12^{\text {th }}$ Global Congress on Manufacturing and Management, GCMM 2014, Procedia Enigineering, p. 97.

6. Bapi Saha, Ajitesh Paul, Pratihari HK (2017) Examination of Genuine and Fake Images by Histogram and Edge detection method- A case study. Journal of Forensic Investigation 5(2).

7. Gonzalez RC, Woods RE (2001) Digital Image Processing ( $3^{\text {rd }}$ edn). Upper Saddle River, Prentice Hall, USA.

8. Gonzalez RC, Woods RE, Eddins SL (2004) Digital Image Processing using MATLAB, Upper Saddle River, Prentice Hall, USA.

\section{Your next submission with Juniper Publishers will reach you the below assets}

- Quality Editorial service

- Swift Peer Review

- Reprints availability

- E-prints Service

- Manuscript Podcast for convenient understanding

- Global attainment for your research

- Manuscript accessibility in different formats

( Pdf, E-pub, Full Text, Audio)

- Unceasing customer service

Track the below URL for one-step submission https://juniperpublishers.com/online-submission.php 